\title{
Inverse relation of serum Helicobacter pylori antibody titres and extent of intestinal metaplasia
}

\author{
H Osawa, F Inoue, Y Yoshida
}

\begin{abstract}
Aims-To clarify the relation between the serum titre of anti-Helicobacter pylori (H pylori) antibody and the extent of intestinal metaplasia of the gastric mucosa. Methods-The serum anti-H pylori IgG titres of 95 asymptomatic individuals (mean age 65 years) undergoing an annual health examination were measured and compared with the extent of intestinal metaplasia (absent, moderate, or extensive), determined by examination of multiple endoscopic mucosal biopsy specimens. Serum pepsinogen I (PGI) levels, as a marker for gastric atrophy, were also measured.

Results-The prevalence of seropositivity for $H$ pylori antibody was high $(>80 \%)$, regardless of the extent of metaplasia. However, there was a negative association between the extent of metaplasia and the anti-H pylori titre: $75 \%$ of the subjects in the group without metaplasia had high $(3+)$ antibody levels, as did $43 \%$ with moderate, and $37 \%$ with extensive metaplasia (absent $v$ extensive). The inverse relation between the titre and the extent of metaplasia was evident when examined in those with normal PGI (>30 ng/ml), whereas no such relation was apparent in subjects with low PGI ( $\leq 30 \mathrm{ng} / \mathrm{ml})$.
\end{abstract}

Conclusions-The anti-H pylori titre correlates inversely with the extent of intestinal metaplasia, particularly in subjects with less marked gastric atrophy. (f Clin Pathol 1996;49:112-115)

Nishiarita Kyoritsu Hospital, Japan: Department of Internal Medicine

H Osawa

Department of Surgery

F Inoue

Department of Integrated Medicine, Omiya Medical Centre, Jichi Medical

School, Japan

Y Yoshida

Correspondence to: Hiroyuki Osawa MD, Omiya Medical Centre, Jich Medical School, 847-1 Amanuma, Omiya, Saitama 330, Japan.

Accepted for publication 18 October 1995
Keywords: extent of intestinal metaplasia, anti-Helicobacter pylori IgG titre, gastric atrophy

Helicobacter pylori, first isolated by Warren and Marshall in 1983, has been implicated in the pathogenesis of peptic ulcer. ${ }^{12}$ Its relation to particularly in patients with intestinal-type carcinoma with underlying intestinal metaplasia. ${ }^{34}$ Conversely, $H$ pylori has been reported to occur infrequently in areas of intestinal metaplasia..$^{5-9}$ Until recently, the techniques available for the detection of $H$ pylori (isolation-culture, assessment of urease activity, and microscopic examination after Gram staining ${ }^{10}$ all required biopsy specimens of the gastric mucosa. The problem with all these techniques is that they yield no information about infection in any part gastric cancer has been also noted recently, of the gastric mucosa other than the site of biopsy. The difficulty in distinguishing endoscopically mucosa with mild to moderate intestinal metaplasia from normal mucosa has complicated these direct sampling methods further, when the relevance of $H$ pylori infection to intestinal metaplasia is discussed.

Recently, enzyme linked immunosorbent assays (ELISA) for anti- $H$ pylori antibodies in serum have been developed. ${ }^{11-14}$ Studies on the effect of bacterial eradication on the antibody titre suggest strongly that the antibody titre reflects the current state of $H$ pylori infection in the entire gastric mucosa. ${ }^{15}$ We have used one of these ELISAS to evaluate the status of $H$ pylori infection in a cohort study for the screening of gastrointestinal disorders. We estimated the anti- $H$ pylori antibody titres and compared them with the degree of intestinal metaplastic extension evaluated histologically by examination of multiple site biopsy specimens. The relation between $H$ pylori infection and gastric atrophy, which frequently leads to intestinal metaplasia, was also examined by comparing the antibody titres with the serum levels of pepsinogen I (PGI), a marker of atrophic gastritis. ${ }^{16-18}$

\section{Methods}

SUBJECTS

Subjects were 95 asymptomatic individuals in their sixties ( 30 men and 65 women, mean age 64.8 years) from 104 who requested gastroscopy as a part of a health examination in a town in Kyushu island in 1992. None of the 95 individuals recruited was taking any medication at the time of the examination. Nine individuals who had a history of peptic ulcer or gastric surgery, abdominal pain and dyspepsia, or were currently taking antacids, $\mathrm{H}_{2}$ receptor antagonists, proton pump inhibitors, antibiotics, steroids, or non-steroidal anti-inflammatory drugs, were excluded from the study. All gave informed written consent.

SERUM AND BIOPSY SPECIMENS

After endoscopic examination for gastric mucosal abnormality including cancer and polyp, two mucosal biopsy specimens were taken from each of the following five sites on the lesser curvature : (1) antrum, (2) angulus, (3) lower body, (4) middle body, and (5) upper body. The specimens were fixed immediately in $4 \%$ 
neutral buffered formalin and processed for histological examination.

Sera were separated within one hour of blood sampling and stored at $-20^{\circ} \mathrm{C}$ until assayed.

ELISA FOR $H$ PYLORI IgG

Serum anti- $H$ pylori antibody titres were measured using a semiquantitative IgG ELISA kit (GAP Test IgG, Biomerica) in accordance with the manufacturer's instructions. ${ }^{12} 13$ This ELISA uses a DEAE ion exchange, chromatography purified $H$ pylori antigen. Serial twofold dilutions $(1: 2-1: 16)$ of positive and negative control sera were assayed in duplicate on each ELISA plate to determine the cut off index for semiquantitative analysis based on the positive/negative ratio. Semiquantitative titres of $3+, 2+, 1+$, and 0 were assigned to the positive/negative ratio obtained with $1: 2$, $1: 4,1: 8$, and $1: 16$ dilutions respectively of the positive control. Subjects with semiquantitative titres of $3+, 2+$, and $1+$ were defined as seropositive. Subjects with a titre of 0 or positive/negative ratio lower than the $1: 16$ dilution of the positive control serum were considered to be seronegative.

SERUM CONCENTRATIONS OF PEPSINOGEN I Serum pepsinogen I concentrations were determined using a competitive binding double antibody radioimmunoassay kit (Dainabot) following the manufacturer's instructions. ${ }^{19}$

\section{PATHOLOGICAL ASSESSMENT AND}

\section{CLASSIFICATION}

The biopsy specimens were routinely processed and stained with haematoxylin and eosin. The presence or absence of intestinal metaplasia was determined by a single pathologist throughout the study.

The extent of histological changes was assessed from the biopsies taken from the five different sites previously described, and was assigned to groups showing absent, moderate, or extensive intestinal metaplasia.

As metaplastic changes appear first at the antrum or angulus of the stomach and extend towards the upper body, ${ }^{20}$ subjects who showed metaplasia in the upper gastric body were defined as the group with extensive intestinal metaplasia. Subjects without metaplasia showed no metaplastic changes in any biopsy specimens. The group with moderate intestinal metaplasia included subjects in whom changes were detected in one or more specimens from the antrum, angulus, lower body and/or middle body, but not in the upper body.

We also allocated subjects to two subgroups according to their serum PGI concentrations: a low PGI group (PGI $\leq 30 \mathrm{ng} / \mathrm{ml}$ ) with severe atrophic gastritis, ${ }^{16-19}$ and a normal PGI group (PGI $>30 \mathrm{ng} / \mathrm{ml}$ ) with absent or lesser degrees of atrophic gastritis, irrespective of the extent of intestinal metaplasia.
Table 1 The prevalence of subjects with $\mathrm{H}$ pylori infection in three groups classified according to the extent of intestinal metaplasia

\begin{tabular}{llll}
\hline \multirow{4}{*}{ Intestinal metaplasia } \\
\cline { 2 - 4 } & None & Moderate & Extensive \\
\hline Normal PGI & $19 / 19$ & $11 / 12$ & $18 / 19$ \\
Low PGI & $5 / 7$ & $10 / 11$ & $20 / 27$ \\
Total & $24 / 26(92 \%)$ & $21 / 23(91 \%)$ & $38 / 46(83 \%)$ \\
\hline
\end{tabular}

PGI = pepsinogen $I$.

\section{STATISTICAL METHODS}

The Wilcoxon rank sum test was used to compare the titre of anti- $H$ pylori antibody between the groups with intestinal metaplasia (extensive or moderate) and the group without changes. The Bonferroni correction with $t$ test was used to compare the PGI levels among the three groups. Probability $(p)$ values less than 0.05 were considered to indicate a significant difference.

\section{Results}

ANTI- $H$ PYLORI IgG TITRE AND INTESTINAL METAPLASIA

Eighty three of the 95 subjects (87\%) examined had positive antibodies to $H$ pylori. The prevalence of $H$ pylori positivity was uniformly high in all groups irrespective of the extent of intestinal metaplasia (table 1). Subjects who were anti- $H$ pylori IgG negative were excluded from further analysis since they were considered not to have any history of $H$ pylori infection.

Among the 83 seropositive subjects, 24 had no intestinal metaplasia according to our classification, 21 had moderate intestinal metaplasia, and 38 extensive intestinal metaplasia. The percentage of seropositive patients in these groups was similar $(92 \%, 91 \%$, and $83 \%$ respectively). However, there was a negative association between the extent of metaplasia and the anti-H pylori titre. The prevalence of a high $(3+)$ titre of anti- $H$ pylori antibody was $75 \%$ in the group without metaplasia, $43 \%$ in the group with moderate metaplasia, and $37 \%$ in the group with extensive metaplasia. The difference was statistically significant between the group without metaplasia and the group with extensive metaplasia $(p=0.007$, table 2$)$.

\section{ANTI-H PYLORI IgG TITRE AND GASTRIC ATROPHY}

Table 3 shows the proportions of subjects with low $(1+)$, medium $(2+)$, and high $(3+)$ titres

Table 2 The prevalence of subjects with high titre $(3+)$, medium titre $(2+)$, and low titre $(1+)$ of anti-H pylori IgG in three groups classified by the extent of intestinal metaplasia

\begin{tabular}{|c|c|c|c|}
\hline & \multicolumn{3}{|c|}{ Anti-H pylori IgG titre, $n(\%)$} \\
\hline & $1+$ & $2+$ & $3+$ \\
\hline Without metaplasia $(\mathrm{n}=24)$ & $1(4)$ & $5(21)$ & $18(75)$ \\
\hline $\begin{array}{l}\text { Moderate intestinal } \\
\text { metaplasia }(n=21) \\
\text { Extensive intestinal }\end{array}$ & $1(5)$ & $11(52)$ & $9(43)$ \\
\hline metaplasia* $(n=38)$ & $5(13)$ & $19(50)$ & $14(37)$ \\
\hline
\end{tabular}

${ }^{*} \mathrm{p}=0.007 v$ without metaplasia. 
Table 3 The prevalence of subjects with high titre $(3+)$, medium titre $(2+)$, and low titre $(1+)$ of anti-H pylori IgG in the normal and the low pepsinogen I groups

\begin{tabular}{llll}
\hline & \multicolumn{4}{l}{ Anti-H pylori IgG titre, $n$ (\%) } \\
\cline { 2 - 4 } & $1+$ & $2+$ & $3+$ \\
\hline Normal $(\mathrm{n}=48)$ & $2(4)$ & $18(38)$ & $28(58)$ \\
Low* $(\mathrm{n}=35)$ & $5(14)$ & $17(49)$ & $13(37)$ \\
\hline$* \mathrm{p}=0.040$ v normal. & & &
\end{tabular}

in the group with normal PGI $(>30 \mathrm{ng} / \mathrm{ml})$ and in that with low PGI $(\leq 30 \mathrm{ng} / \mathrm{ml})$. The proportion of subjects with high titre is significantly higher in the normal PGI group compared with that in the low PGI group $(p=$ $0.040)$.

This inverse relation between the anti- $H$ pylori IgG titre and the extent of intestinal metaplasia was more evident among patients with normal PGI levels ( $>30 \mathrm{ng} / \mathrm{ml}$ ). The prevalence of a high $(3+)$ titre of anti- $H$ pylori antibody was $84 \%$ in the group without metaplasia, $45 \%$ in the group with moderate metaplasia, and $39 \%$ in the group with extensive metaplasia. The difference in prevalence was statistically significant between the group without metaplasia and the group with moderate metaplasia $(p=0.025)$, as well as between the group without metaplasia and the group with extensive metaplasia $(p=0.004)$ (table 4$)$. In the low PGI group, only five of 35 subjects $(14 \%)$ had biopsies showing no intestinal metaplasia, while $20(57 \%)$ had extensive intestinal metaplasia. The anti- $H$ pylori IgG titres in the low PGI group were not significantly different between these groups, and the prevalence of high titres in each group tended to be lower than in the normal PGI group (table 5).

\section{PGI CONCENTRATIONS AND INTESTINAI}

METAPLASIA

Serum PGI was $38.5($ SD $18 \cdot 2) \mathrm{ng} / \mathrm{ml}$ in the group without intestinal metaplasia, $32 \cdot 5$

Table 4 The prevalence of subjects with high titre $(3+)$, medium titre $(2+)$, and low titre $(1+)$ of anti-H pylori IgG in three groups classified by the extent of intestinal metaplasia, in the subgroup with normal pepsinogen I levels

\begin{tabular}{llll}
\hline & \multicolumn{4}{l}{ Anti-H pylori IgG titre, $n(\%)$} \\
\cline { 2 - 4 } & $1+$ & $2+$ & $3+$ \\
\hline $\begin{array}{l}\text { Without metaplasia }(\mathrm{n}=19) \\
\text { Moderate intestinal }\end{array}$ metaplasia* $(\mathrm{n}=11)$ & $0(0)$ & $3(16)$ & $16(84)$ \\
$\begin{array}{c}\text { Extensive intestinal } \\
\text { metaplasiaf }(\mathrm{n}=18)\end{array}$ & $0(0)$ & $6(55)$ & $5(45)$ \\
\hline
\end{tabular}

${ }^{*} \mathrm{p}=0.025 v$ without metaplasia; $\dagger \mathrm{p}=0.004 v$ without metaplasia.

Table 5 The prevalence of subjects with high titre $(3+)$, medium titre $(2+)$, and low titre $(1+)$ of anti-H pylori $I g G$ in three groups classified by the extent of intestinal metaplasia, in the subgroup with low pepsinogen I levels

\begin{tabular}{|c|c|c|c|}
\hline & \multicolumn{3}{|c|}{ Anti-H pylori $I g G$ titre, $n(\%)$} \\
\hline & $1+$ & $2+$ & $3+$ \\
\hline \multirow{3}{*}{$\begin{array}{l}\text { Without metaplasia }(n=5) \\
\text { Moderate intestinal } \\
\text { metaplasia }(n=10) \\
\text { Extensive intestinal } \\
\text { metaplasia }(n=20)\end{array}$} & $1(20)$ & $2(40)$ & $2(40)$ \\
\hline & $1(10)$ & $5(50)$ & $4(40)$ \\
\hline & $3(15)$ & $10(50)$ & $7(35)$ \\
\hline
\end{tabular}

$(15.7) \mathrm{ng} / \mathrm{ml}$ in the group with moderate intestinal metaplasia, and $30 \cdot 1(22 \cdot 7) \mathrm{ng} / \mathrm{ml}$ in the group with extensive intestinal metaplasia. Thus PGI concentrations tended to decrease as intestinal metaplasia extended, although the differences were not statistically significant among these groups.

\section{Discussion}

Although it is thought that $H$ pylori may play a role in the malignant transformation of intestinal metaplasia, the bacteria have not often been detected in the gastric mucosae of patients with intestinal metaplasia. ${ }^{5-9}$ The altered milieu in the areas of intestinal metaplasia, ${ }^{9}$ including an increase of secretory IgA and less acidity compared with the normal gastric mucosa, may explain the decreased colonisation of $H$ pylori in the metaplastic mucosa. IgA in the gastric juice may be important in inhibiting bacterial adhesion to the epithelial surface, ${ }^{5721}$ and the decreased acidity may inhibit the proliferation of $\mathrm{H}_{\text {pylori }}{ }^{822}$ Accordingly, it is essential to take biopsy specimens of mucosa not involved in the metaplasia and examine them for $H$ pylori in such patients. However, the endoscopic diagnosis of mild or moderate metaplasia is quite difficult without histological examination. Therefore $H$ pylori detection by biopsy specimen examination may not be very reliable, particularly in elderly Japanese patients in whom intestinal metaplasia of the stomach is common.

Recently, serological techniques for detecting $H$ pylori have been developed and several studies have been conducted to compare the results of serological tests and direct detection in biopsy specimens. ${ }^{11-13}$ However, no studies referring to the serological titre and extent of intestinal metaplasia have, to our knowledge, been reported. In the present study, we compared the anti- $H$ pylori IgG titre, evaluated by a sensitive and highly specific ELISA ${ }^{1213}$ and the extent of intestinal metaplasia, evaluated by histological examination of biopsy specimens taken from multiple sites.

Anti- $H$ pylori antibodies were detected in over $80 \%$ of the subjects examined, regardless of the extent of intestinal metaplasia. This result agrees with a previous report ${ }^{14}$ that the prevalence of $H$ pylori infection is high (70-80\%) and relatively constant in Japanese persons born before 1950 . The anti- $H$ pylori IgG titre was related inversely to the extent of intestinal metaplasia. As the serum antibody titre is considered to reflect the current state of $H$ pylori infection, our results suggest that the number of bacteria present in gastric mucosa decreased in proportion to the extent of intestinal metaplasia. Consequently, the prevalence of seropositivity in patients in whom $H$ pylori is not detected in biopsy specimens would increase as intestinal metaplasia extends. The discrepancies between serological evaluation and direct detection in previous studie ${ }^{11-13}$ can thus be explained.

Next, we examined the relation between the anti- $H$ pylori titre and the severity of gastric 
mucosal atrophy, because the bacterium has also been reported to be absent in severely atrophic mucosa. ${ }^{8}$ The severity of mucosal atrophy was evaluated by measuring the serum PGI levels. Samloff $e t$ al $^{18}$ reported that in mild or moderate atrophic gastritis, PGI concentrations did not differ significantly from normal, whereas they were reduced in severe atrophic gastritis. We found that the prevalence of high anti- $H$ pylori antibody titres was greater in the group with normal PGI concentrations than in the group with low PGI. The inverse relation between the anti- $H$ pylori IgG titre and the extent of intestinal metaplasia was statistically significant among patients with normal PGI concentrations, but not among those with a low PGI. This serological result suggests that severe gastric mucosal atrophy itself suppresses the number of bacteria, regardless of the presence of intestinal metaplasia, although the small number of patients without intestinal metaplasia in this group made precise evaluation difficult. The interpretation of the relation between $H$ pylori infection and intestinal metaplasia in the low PGI group is further complicated by the high frequency of intestinal metaplasia in patients with severe atrophic gastritis. These results show that the anti- $H$ pylori IgG titre has a strong inverse correlation with the extent of intestinal metaplasia, at least in subjects with less marked atrophic changes.

Our study showed that $H$ pylori seropositivity is quite common in elderly patients, even in those with intestinal metaplasia, despite reports that the organism cannot be detected histologically in the gastric mucosa of such patients. This indicates that $H$ pylori infection could occur concurrently or at least may have occurred in the recent past. Another interesting finding of this serological study was that the antibody titre showed an inverse correlation with the extent of metaplasia, implying that the bacterial load may decrease quantitatively as the metaplasia extends. Considering the high risk of gastric cancer in elderly patients with intestinal metaplasia, ${ }^{423}$ in whom endoscopic diagnosis is not necessarily easy, those with low anti- $H$ pylori antibody titres should be observed closely, even if marked gastric atrophy is not present.

The authors are grateful to $\operatorname{Dr} M$ Kawakami for numerous discussions during the preparation of the manuscript.
1 Warren JR, Marshall BJ. Unidentified curved bacilli on gastric epithelium in active chronic gastritis. Lancet 1983; i: $1273-5$.

2 Graham DY. Campylobacter pylori and peptic ulcer disease. Gastroenterology 1989;96:615-25.

3 Howson CP, Hiyama T, Wynder, EL. The decline in gastric cancer: epidemiology of an unplanned triumph. Epidemiol Rev 1986;8:1-27.

4 Parsonnet J, Vandersteen D, Goates J, Sibley RK, Pritikin $\mathrm{J}$, Chang Y. Helicobacter pylori infection in intestinal- and diffuse-type gastric adenocarcinoma. $\mathcal{F}$ Natl Cancer Inst 1991;83:640-3.

5 Tsutsumi Y, Nagura H, Watanabe K. Immune aspects of intestinal metaplasia of the stomach: an immunohistochemical study. Virchows Arch [Pathol Anat] 1984; 403:345-59.

6 Johnston BJ, Reed PI, AIi MH. Campylobacter-like organisms in duodenal and antral endoscopic biopsies: relationship to inflammation. Gut 1986;27:1132-7.

7 Wyatt JI, Rathbone BJ, Heatley RV. Local immune response to gastric Campylobacter in nonulcer dyspepsia. $\mathcal{f}$ Clin Pathol 1986;39:863-70.

8 Karnes WE, Samloff IM, Siurala M, Kekki M, Sipponen P, Kim SWR, et al. Positive serum antibody and negative tissue staining for Helicobacter pylori in subjects with tissue staining for Helicobacter pylori in subjects with
atrophic body gastritis. Gastroenterology 1991;101:167-74.

9 Craanen ME, Blok P, Dekker W, Ferwerda J, Tytgat GNJ. Subtypes of intestinal metaplasia and Helicobacter pylori. Gut 1992;33:597-600.

10 Marshall BJ, Warren JR, Francis GJ, Langton SR, Goodwin CS, Blincow ED. Rapid urease test in the management of Campylobacter pyloridis-associated gastritis. Am. $\mathcal{F}$
Gastroenterol 1987;82:200-10.

11 Newell DG, Johnston BJ, Ali MH, Reed PI. An enzymelinked immunosorbent assay for the serodiagnosis of Campylobacter pylori-associated gastritis. Scand $\mathcal{f}$ Gastroenterol 1988;23(Suppl 142):53-7.

12 Hoek FJ, Noach LA, Rauws EAJ, Tytgat NJ. Evaluation of the performance of commercial test kits for detection of Helicobacter pylori antibodies in serum. $\mathcal{F}$ Clin Microbiol 1992;30:1525-8.

13 Crabtree JE, Shallcross TM, Heatley RV, Wyatt JI. Evaluation of a commercial ELISA for serodiagnosis of Helicobacter pylori infection. 7 Clin Pathol 1991;44:326-8.

14 Asaka M, Kimura T, Kudo M, Takeda H, Mitani S, Miyazaki $T$, et al. Relationship of Helicobacter pylori to serum pepsinogens in an asymptomatic Japanese population. pepsinogens in an asymptomationtorology 1992;102:760-6.

15 Kosunen TU, Seppala K, Saruna S, Sipponen P. Diagnostic value of decreasing IgG, IgA, and IgM antibody titres after eradication of Helicobacter pylori. Lancet 1992;339: 893-5.

16 Miki K, Ichinose $M$, Shimizu A. Serum pepsinogens as a screening test of extensive chronic gastritis. Gastroenterol fpn 1987;22:133-41.

17 Stemmermann GN, Samloff IM, Nomura AM, Heilbrun LK. Serum pepsinogens I, II and stomach cancer. Clin Chim Acta 1987;163:191-8.

18 Samloff IM, Varis K, Ihamaki T, Siurala M, Rotter JI. Relationships among serum pepsinogen I, serum pepsinogen II, and gastric mucosal histology: a study in relatives of patients with pernicious anemia. Gastroenterology 1982;83:204-9.

19 Ichinose M, Miki K, Furihata C, Kageyama T, Hayashi R, Oka H, et al. Radioimmunoassay of serum group I and group II pepsinogens in normal controls and patients with various disorders. Clin Chim Acta 1982;126:183-91.

20 Kimura K, Satoh K, Yoshida Y, Taniguchi Y, Ido K, Takemoto T. Chronological extension of atrophic gastritis and intestinal metaplasia in Japanese. Eur $\mathcal{f}$ Gastroenterol Hepatol 1993;5(Suppl 1):S85-91.

21 Rathbone BJ, Wyatt JI, Worsley BW, Shires SE, Trejdosiewicz LK, Heatley RV, et al. Systemic and local antibody responses to gastric Campylobacter pyloridis in nonulcer dyspepsia. Gut 1986;27:642-7.

22 Wyatt JI, Shallcross TM, Crabtree JE, Heatley RV. Helicobacter pylori, gastritis, and peptic ulceration in the elderly. F Clin Pathol 1992;45:1070-4.

23 Correa P. Precursors of gastric and esophageal cancer. Cancer 1982;50(Suppl 11):2554-65. 